\title{
Roles of Technology in Improving Perishable Food Supply Chains
}

\author{
Mona Haji ${ }^{1}$, Laoucine Kerbache ${ }^{1,2}\left(\mathbb{0}\right.$, Mahaboob Muhammad ${ }^{1}\left(\mathbb{D}\right.$ and Tareq Al-Ansari ${ }^{1,3, *}$ (i) \\ 1 Division of Engineering Management and Decision Sciences, College of Science and Engineering, \\ Hamad Bin Khalifa University, Qatar Foundation, 34110 Doha, Qatar; mhaji@hbku.edu.qa (M.H.); \\ lakerbache@hbku.edu.qa (L.K.); mkhadermuhammad@hbku.edu.qa (M.M.) \\ 2 Information Systems and Operations Management, HEC Paris, 78351 Jouy-en-Josas, France \\ 3 Division of Sustainable Development, College of Science and Engineering, Hamad Bin Khalifa University, \\ Qatar Foundation, 34110 Doha, Qatar \\ * Correspondence: talansari@hbku.edu.qa
}

Received: 4 October 2020; Accepted: 18 November 2020; Published: 7 December 2020

check for updates

\begin{abstract}
Food supply chains are considered to be more complex systems than other types of supply chains. This complexity is due to the continuous changes taking place, particularly in ensuring the quality of food products throughout the entire supply chain, from growing, procurement of resources, production, and management of stock, to distribution to the final consumers. For that, food supply chain markets have become more highly developed in the use of modern technologies, and have begun to implement them in their logistical systems to satisfy their customers' needs. The main objectives of this review are to identify the different technological implementations in different phases of the food supply chain processes and point out the key factors for using technologies to improve the characteristics of the perishable food supply chain. A total number of 137 articles were analyzed in this research to achieve these review objectives. Some of the various technologies found in different phases of the food supply chain were radio frequency identification (RFID), the Internet of Things (IoT), blockchain, three-dimensional printing (3DP), autonomous vehicles, and unmanned aerial vehicles (UAVs). These technologies were found in different phases of the food supply chain and improved the efficiency of supplying perishable foods. The review identified different characteristics of the perishable food supply chain. The main finding indicated that technological implementation enhances the efficiency and sustainability of the food supply chains and helps to retain perishable food characteristics.
\end{abstract}

Keywords: food supply chain; traceability technologies; perishable foods; supply chain innovation

\section{Introduction}

In recent years, with the rapid growth of food industries and radical changes in people's dietary habits and lifestyles, food awareness has increased for most consumers. Modern customers are more concerned about the safety and the quality of the food that they eat. Food safety is understood to encompass food that is free from impurities and substances that may cause the growth of bacteria harmful to people's safety and lives [1]. The manipulation of food can cause severe damage to the health and safety of community members, and perpetrators are punished with severe penalties to deter such acts from spreading. Food scandals have recently revealed harmful products in the China market, such as "Sudan red," "clenbuterol," "Sanlu toxic milk powder," and "trench oil." Food consumers in the China market have lost their trust in the provided food safety and quality. Food safety problems are not limited to China; different cases have been reported in Europe as well, such as Escherichia coli in 
hamburgers, Salmonella in eggs, poultry, and pork, Listeria in patés and cheeses, and the "horse meat scandal" in 2013 [2].

According to Hammoudi et al. [3], the World Health Organization (WHO) has defined foodborne illness as diseases caused by the penetration of foreign bodies into food, which can lead to food poisoning in many cases. Foodborne diseases are increasing annually and are impacting the health of people across the globe. In the United States, for instance, one in six people suffer from illnesses that unhealthy food causes, resulting in 128,000 hospitalizations and 3000 deaths every year [4]. Although it is unlikely that food illnesses will ever be eradicated entirely, primarily due to economic factors, they can be reduced through continuous monitoring of the food supply chain system. The fact is, consumers expect that governments monitor food products, thus maintaining their health and protecting them from fraudulent food organizations.

Food supply chains are considered complex and dynamic supply chains that are measured in the different phases impacting the quality, cost, and delivery time of a product, which could take place in the supply chain at the different stages ranging from the agriculture phase until the point at which a product reaches the final consumers [5]. Effective food supply chain management depends on several factors. For instance, Pang et al. [6] noted that an efficient food supply chain could ensure timely delivery and prompt customer support and decrease the total costs involved in the supply chain. Furthermore, efficient food supply chain management can increase profit and cash flow in companies connected to these processes and those who participate in the supply chain. It is, therefore, critical to first understand what constitutes a good food supply chain. In essence, a good performing food supply chain is expected to provide the required amount of food while operating within safety standards, thus delivering good quality food that is accessible and affordable.

Different types of technologies have been integrated into the food supply system to mitigate risks, maximize efficiency, and manage complexities [7]. Moreover, modern technologies have become much more user-friendly and are used for the different activities in the food supply chain, such as planting, harvesting, preparation, processing, packaging, transportation, and inventory management. Technologies are utilized primarily to speed up the processes, meet the growing global food demand at the right time, and track food origin to assess food quality and safety aspects accordingly. The increased use of technology in the food supply system has helped increase and sustain perishable food safety and quality. According to Khan, Khalid, and Iqbal [8], new technologies have also empowered producers and manufacturers with more capacity to monitor the different phases of the food supply chain more efficiently.

\subsection{Defining the Food Supply Chain}

The term "food supply chain" refers to a system consisting of a series of processes that define the transformation of agricultural products into a form that can be served on a plate and consumed.

Outputs of a food supply chain often include what are termed "perishable foods." Perishable food refers to a category of commodities that are subject to quality damage during their manufacturing stage, storage, shipping, or handling. All fresh foods, such as bakery products, fruits, vegetables, dairy products, and meats, are part of the perishable food supply [9]. Notably, managing fresh foods and perishable products is more complicated than managing any other supply chain goods due to their short shelf lives [10]. The essence of which depends on monitoring time and temperature factors throughout all phases of the supply chain as they critically affect the quality of food [11]. Essentially, the longer the length of time in the transportation phase post-manufacture or processing, the larger the likelihood of deterioration in the quality of the food.

Perishable food materials are also temperature-sensitive, and, therefore, they are unusually susceptible to damage during processing, packaging, transportation, and handling [12]. According to Smith and Sparks [13], the temperature can also adversely affect the processing, storage, delivery, and shelf life of fresh foods. As such, different foods should be kept at different temperature ranges to ensure their safety and healthfulness, and interventions should be implemented to maintain controlled environmental conditions and protect food quality, safety, waste reduction, and profits [14]. 
The processes involved in the perishable food supply chain include various intermediate steps in each industry through which the raw materials or crops undertake before being supplied to the market. The initial phase involves the different steps in the processing of crops in the agricultural industries. The key activities in this phase include planting, cutting or harvesting, transport, processing, and delivery to the food processing industry. Materials are delivered to the processing factories where the activities involve sorting, cutting, refining, or chemical treating, cleaning, packaging, and, finally, delivery to the distributors [15]. In terms of retailing, perishable foods require additional maintenance attributes vital to delivering satisfactory products to the customers at the end of the supply chain, as opposed to the direct selling to retailers after primary processing, such as in the case of grains and cereals [16]. Figure 1 shows the processes involved in the food supply chain.

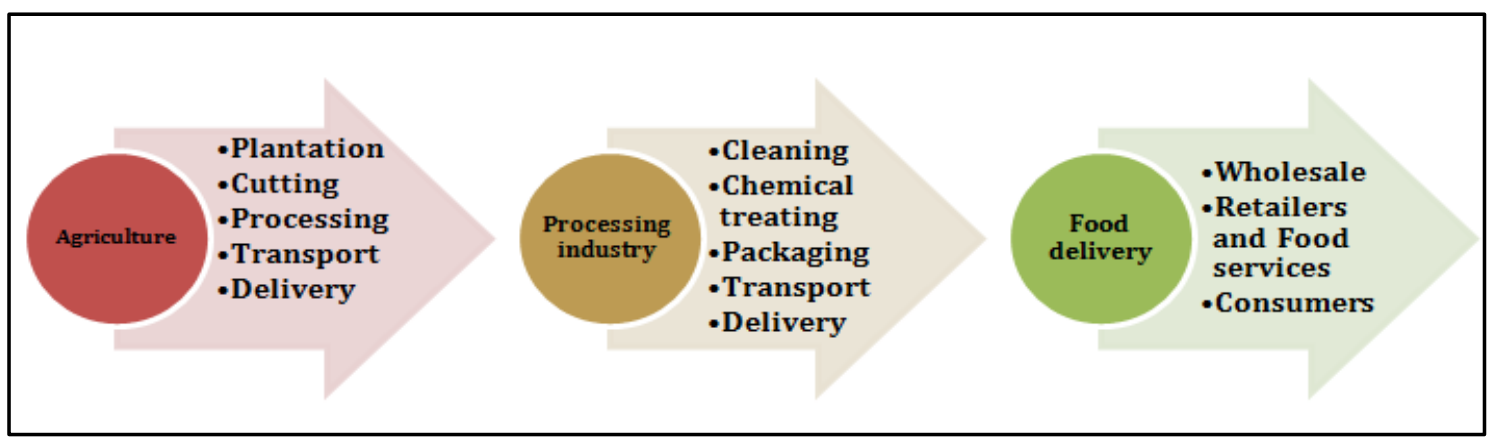

Figure 1. Processes involved in the perishable food supply chain after Bosona and Gebresenbet [15].

\subsection{Review Objectives}

In terms of previously published reviews related to technology integration in food supply chains, Büyüközkan and Göçer [17] reviewed the state-of-the-art of existing digital supply chain (DSC) literature and the value creation gained from implementing emerging technologies for logistics and supply chain services, providing benefits, weaknesses, challenges and the success factors of DSC. With a focus on agriculture, Opara [18] reviewed the basic concepts of traceability in agriculture and highlighted various tools for food traceability, which have been utilized mainly for labeling and identification, storage and communication, and geospatial science such as remote sensing (RS), geographic information systems (GIS), and global positioning systems (GPS). Ruiz-Garcia et al. [19] focused on promising wireless sensing technologies, such as radio frequency identification (RFID) for precision agriculture and perishable food supply chain traceability. Zhang and Kovacs [20] reviewed the different applications of unmanned aerial vehicles for precision agriculture and remote sensing platforms. Dasgupta et al. [21] provided a detailed overview of the various applications of nanotechnology in the food sector from farm to plate and included technologies used for food processing, packaging, delivery, and quality control. Ray [22] reviewed various Internet of Things (IoT) applications for smart agriculture to provide intelligent services. Walter et al. [23] reviewed smart farming through the use of autonomous vehicles or unmanned aerial vehicles to promote sustainable agriculture in applications such as fertilizer, weeding, or harvesting. Sun et al. [24] reviewed the different uses of three-dimensional (3D) printing as an emerging technology for food fabrication and their impacts on the manufacturing stage of the supply chain. Khan, Khalid, and Iqbal [8] reviewed the significant potential for implementing robotics technology in food manufacturing. Brody et al. [25] reviewed the latest innovation in food packaging for the intelligent packaging process. Duncan [26] reviewed several nanomaterials applications used for food packaging based on antimicrobial agents to ensure consumer's safety. Ghaani et al. [27] provided an overview of intelligent packaging technologies to ensure the safety, quality, and traceability of food products. Li et al. [28] proposed an effective platform for real-time tracking and tracing for packaged food through the supply chain to its point of consumption based on Internet of Things (IoT) technologies, such as quick response (QR) and the RFID to ensure its safety for human use. $\mathrm{Yu}$ and $\mathrm{Yu}$ [29] developed autonomous vehicle technologies for deliveries. Jeppsson and Olsson [30] 
explored the benefits gained by implementing blockchain technology to increase transparency and solve traceability issues that logistics companies face. Angeles [31] reviewed the various applications of RFID technology in the distribution and retailing phases of the supply chain, such as scanning goods from pallets to trailers, and preparing them for shipping. Moreover, the use of RFID in reading tags and updating inventory quantities provides real-time visibility.

Most reviews related to food supply chains have focused on exploring the benefits of technology implementation in particular stages within the food supply chain. The review presented in this study differs as it reviews the integration of technologies throughout the food supply chain from farm to plate. The objectives of the review are to:

(1) Identify the different technological driven interventions throughout the different phases of the food supply chain, which include agriculture, processing, packaging, shipping, and selling, and to discuss their impacts on the efficiency of the perishable foods.

(2) Identify the impact of integrating technologies on the characteristics of the perishable food supply chain.

(3) Identify the impact of integrating technologies on the traceability of the perishable food supply chain.

The review begins with a literature review for each technology. An analysis of the extent of technology implementation in the different phases of the food supply chain that can improve the characteristics of perishable foods follows. The next part focuses on discussing the methodologies of the review conducted for data gathering and analysis. Then, charts used for the findings support the discussion and analysis for the reviewed papers. Finally, the concluding section summarizes the key findings of this review.

\section{Literature Review}

\subsection{Technology Integration in the Food Supply Chain}

This section presents current and future prospects for applying different technologies by actors in the perishable food supply chain network to enhance its efficiency. It further examines the opportunities and challenges of using various technologies in a food supply network that encompasses agriculture, processing, packaging, and shipping. It also provides insight into the need for traceability within the supply chain and the means by which the implementation of technologies can achieve traceability.

Figure 2 shows the process diagram of the fruits and the vegetables and shows their detailed movement in the supply chain. The phases of the perishable food supply chain include agricultural raw materials, processing, packaging, shipping, and selling. For an overview example, fruits and vegetables are crops that fall under the agricultural raw materials. Once the harvesting, threshing, and drying activities are completed, the fruits and vegetables are transported to dedicated storage inside processing factories where they are being sorted, cleaned, cut, or treated chemically. Secondary processing is then applied to the fruits and vegetables and sent to the quality control department for being checked against specific standards and confirm their validity. After that, they are packaged with the proper type of packaging based on the transportation period, shelf life, and the storing temperature. The fruits and vegetables are then transported to their final destinations and sold in retail stores based on customer demands.

\subsubsection{Agricultural Raw Materials}

The agriculture sector is the first phase of food growth and is of great importance. According to Figure 1, which is influenced by Bosona and Gebresenbet [15], agriculture mainly involves planting, seeding, and harvesting crops in the perishable food supply chain. Investments in the agricultural sector have been growing significantly annually as the food industry adopts emerging technological advancements. In fact, the use of modern digital technologies in agriculture can enhance farming 
operations and support strategic decision-making [33]. Kamilaris et al. [34] demonstrated that the most widely used technology in agriculture involves soil and water sensors. According to Sufiyan et al. [35], the cultivation and processing of perishable foods require additional environmental control systems, and these systems act as important determinants for the amount of food utilized and wasted in the supply chain. Weather tracking and satellite imaging technologies are also used in agriculture, which enables easier imaging and examination of crops [18]. Ray [22] studied the potential for minimizing operator workload through the use of automation technologies, which have become common, including the use of autonomous vehicles to identify and sort seedlings, as well as to spray, weed, and harvest crops. Autonomous ground vehicles are also used in monitoring and analyzing crops. Moreover, autonomous vehicles are used for poultry farming activities, such as feeding and milking dairy cows, collecting and sorting eggs, and autonomous cleaning [2]. The CEO of Freelance Robotics company, William Pagnon, confirmed the role of the company in developing different types of autonomous vehicles for agricultural purposes such as tractors and irrigation [36]. In farming, drones have been deployed to monitor the growth of and damages to crops and to apply fertilizers and pesticides on crops. Costa et al. [37] stated that increasing the use of unmanned aircraft in agricultural areas has contributed to boosting the effectiveness of spraying operations. Pilotless aircraft have also been proven effective in monitoring and inspecting livestock.

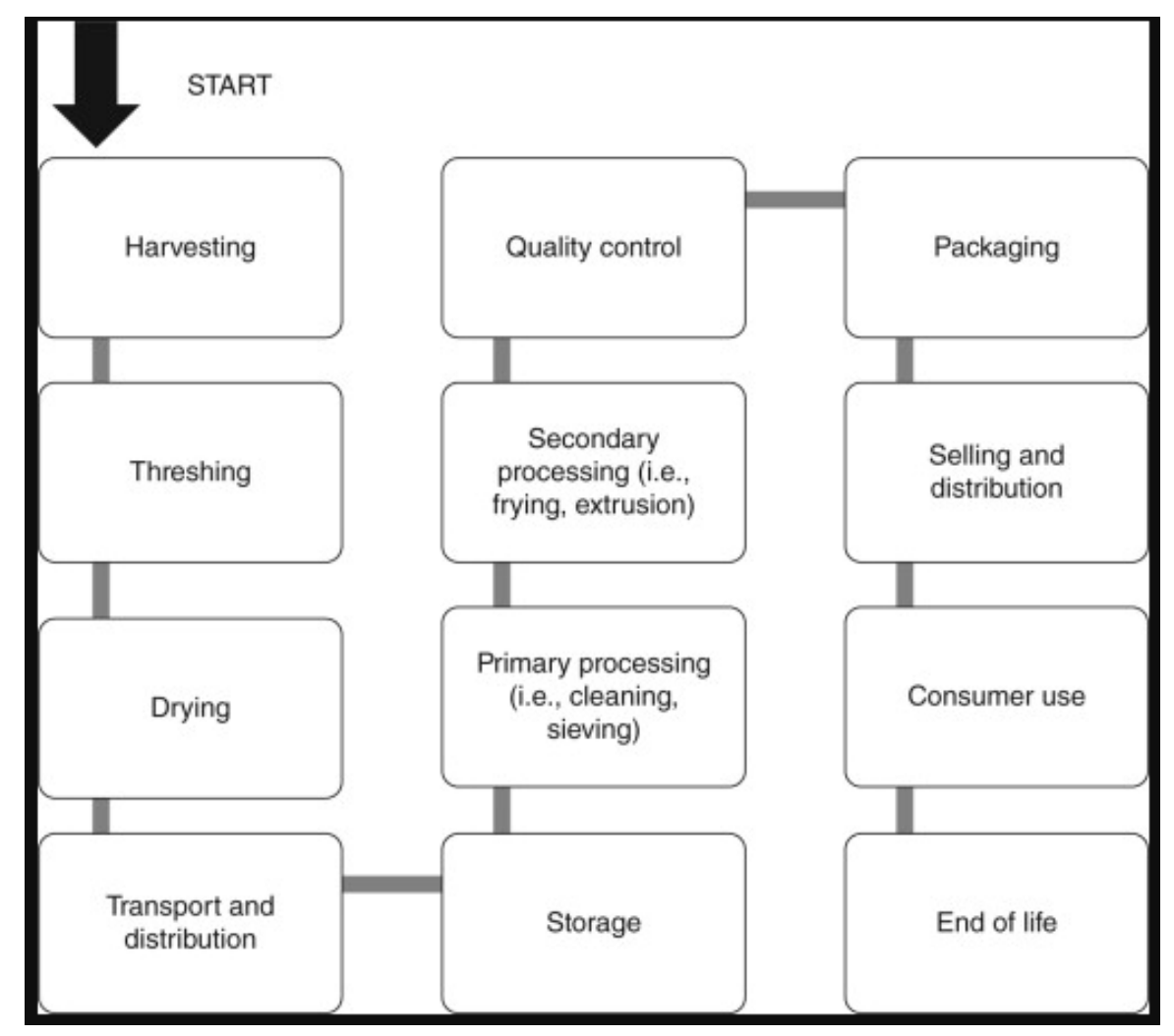

Figure 2. Process diagram for the perishable food supply chain. Adapted from L.A. Pfaltzgraff and J.H. Clark [32].

Although the use of technology provides benefits to agricultural operations, the main challenge in implementing such technological innovations in the agriculture sectors is related to the lack of capital available for investment. These technologies are comparatively expensive for farmers, who are likely to prefer simple and easily coordinated systems in their farming process as part of optimizing their resources [38]. To better popularize the use of such technologies for such farmers, cost-effective and simplified systems with no major complications can create greater opportunities for adoption by farmers, particularly those with little formal schooling. 


\subsubsection{Transformation and Processing}

The transformation and processing of the food system involve two basic steps, cleaning, and transforming crops into food ingredients and converting them to processed food ready for cooking. Transformation and conversion, simply stated, involve the changing of raw materials, such as vegetables or milk, into ingredients such as salad and dairy products. This is also known as the manufacturing or value addition stage. Figure 1 illustrates that transformation and conversion are considered part of the second phase of the perishable food supply chain. With the increasing demand for safe and high-quality food products and increasing demands of consumers all over the world, the implementation of technology within the food processing and conversion phase is also increasing in popularity.

According to Prakash [39], the implementation of technology and innovation can enhance the final condition of food products at this stage. Rong et al. [40] determined that modern technological interventions play an important role in accelerating perishable food conversion, thus ensuring that it remains at a high quality for a more extended period. Pressure processing technologies are the most basic applications in perishable food supply chains [41]. Such technologies are used to maintain the current condition and to improve the longevity of the perishable food material. High-Pressure Processing (HPP) technologies are other alternatives for food-processing technologies that use high hydraulic pressures under reduced temperatures for improving and retaining the nutritional values of perishable food materials [42].

Food conversion can also include 3D printing technologies, which are commonly used in preparing perishable foods such as the production of recombined meat products [43]' dairy products, fish products [44], chocolates and candies [45], and bakery products, such as pizzas and pastries [46]. Similarly, Sun et al. [24] highlighted several potential benefits of using 3D printing technology in food fabrication. Accordingly, 3D food printing can be applied to control the quantity of materials and nutritional contents to create customized color, shape, flavor, nutrition, and even texture. The study concludes that $3 \mathrm{D}$ food printing provides a solution to the design of customized foods and personalized nutritional content.

Alternatively, the use of technologies such as the IoT and cloud computing can significantly reduce the generated amount of carbon in the conversion process of perishable foods, such as meat [47]. The implementation of IoT in food industries evolves the installation of different types of sensors mainly, evolving temperature, and humidity sensors that have been efficient in monitoring the production state along with shipping time and monitoring temperature for ensuring the food products storage environment. The energy consumption is reduced by using IoT, and, hence, the flow of carbon in the environment is also reduced. The adoption of cloud computing in the meat industries allows the stakeholders to minimize carbon emission at appropriate costs and infrastructure. According to Manning and Soon [48], advanced analytics using the IoT and cloud computing provide more substantial advantages for operators in tracking the movement of supplied food materials, as well as for predicting, detecting, and preventing fraudulent activities in the transformation intermediate steps. Furthermore, Mogale et al. [49] stated that applications such as the IoT, cloud computing, and big data analytics have allowed producers to minimize the loss of food products, thereby reducing the overall waste of materials and money.

A major challenge in implementing technological alternatives in the food conversion phase is infrastructure bottlenecks. According to Petersen et al. [50], the complete logistics of perishable food are dependent on the infrastructure management efficiency in the manufacturing and storage facilities. Óskarsdótti and Oddsson [51] identified that infrastructure bottlenecks caused by inadequate management knowledge drive more than $30 \%$ of the processing failures.

\subsubsection{Packaging}

The packaging process is considered one of the most essential activities in food production systems, especially when dealing with perishable food. According to Verghese et al. [52], $40 \%$ of the food meant for human consumption is wasted annually. This waste is equivalent to $10 \%$ of the total energy inputs for one person's weekly food consumption. As such, the value of packaging is vital in this regard, 
as packaging contains and protects the food to be consumed by people. In addition, the quality and safety of delivered food are highly dependent on the packaging stage, and, therefore, the quality of packaging indirectly drives customer satisfaction levels [27]. As Figure 1 shows, the packaging process is also considered part of the second phase of the perishable food supply chain.

Digital and robotic technologies such as filling, handling, and movement are implemented during the food material packaging process. As Khan, Khalid, and Iqbal [8] indicated, such robotic technologies have recently begun to prosper as a leading technology in the food sector. Robots have been utilized in a wide range of situations, such as in food processing, handling, organizing, packing, and food serving. Automation of the simple activities in the food supply chain, such as packaging, can increase efficiency and can assist in developing new value-added services. Many packing companies have implemented various forms of intelligent packaging to protect the quality of perishable food. For example, these technologies include multi-layer barrier and moisture absorbing packaging, both of which are used to eliminate the moisture from the food. Modified Atmosphere Packaging (MAP) is another innovation in which gases are added to fresh foods such as meat, fruit, or vegetables to protect their internal environment. Furthermore, oxygen scavengers, which are powder particles added to the package to remove the oxygen, have been used increasingly in packaging. Recently many companies have also implemented ecological packaging to assist in protecting the environment [52]. Nanotechnology is an emerging technology used with perishable food packaging to retain freshness, minimize waste, ensure food safety, and improve quality [53].

Active packaging has been known as the advanced form of packaging in which the packaging material interacts with food for maintaining a longer shelf life with higher safety and improved quality and hygiene of food [54]. Smart packaging and advanced packing involve the use of sensors with the installation of neural networks and thresholds [55]. Food processors have been used with various machines to produce different products while using only a single packaging line. Cartooning, wrapping, labeling, shrinking, sealing, case and tray forming, caping, cooling and drying, feeding, palletizing, picking and placing (robotic systems), cleaning and sterilizing, and inspection and detecting machines are some of the major machine types that are used as advanced packaging machinery and automation systems [56]. Moreover, the robots are used in food applications in welding and assembly lines. Robotic systems enable the packaging of meat and chocolates into trays rapidly and efficiently [57]. Furthermore, many automated types of machinery have been used for automating the final product due to the demand for increased productivity of the particular food items. The modern control network technology in food industries has improved food productivity, manufacturing, preservation, and handling.

Smart packaging is another major advancement in the food production system, which helps in maintaining product quality throughout the supply chain. Radio-Frequency Identification (RFID) and smart labels have been considered as an easy method for implementation in current packaging formats [58]. Hence, these labels have been efficient in protecting the food from any kind of theft while relocating during the supply chain [55]. Moreover, the smart labels have been used for monitoring the temperature and quality. These labels have been effective in providing product safety assurance to consumers, allowing them to verify the specific product codes and confirm that the product had not been tampered with [59]. These smart labels have also been efficient in preventing recalls and reducing their impacts and identifying any kind of contamination during the supply chain [60]. Another major advantage of smart packaging includes the use of packaging materials involving the absorbance of oxygen that helps in extending the shelf life without the addition of any preservatives. Hence, this type of technology fulfills the consumer's demand concerning clean-label products with an increase in shelf life and more distribution of the product to various geographical locations. Innovation in the world of packaging continues to develop, as scholars are continuously studying and evolving the packaging processes, thus improving customer satisfaction. The subject of packaging is very sensitive and closely related to customers' feedback, so more attention is to be given to this stage. 


\subsubsection{Shipping}

Shipping is the process of moving and transferring goods from the manufacturers and delivering them to customers or retailers. As illustrated in Figure 1, shipping processes are also considered part of the second phase of the perishable food supply chain. Today, shipping services have become much more accurate with the use of improved tracking technology. Accurate tracking services, such as global positioning systems (GPS) technology, are used to detect the location of the consumers or purchases while delivering food materials to the sellers or consumers [61]. The GPS has become a component of the quality control process of the food industry and ensured full visibility of each product throughout the whole supply chain [62]. The use of a GPS system helps track the food transportation vehicle for the delivery at an appropriate time. Some trailer-mounted GPS devices can provide remote diagnostics for the refrigerated trailers, including power status and current temperature readouts. Such remote diagnostics give immediate information when the power to a trailer is interrupted or when temperatures go above safe levels. This enables in reaching out to the driver and alert them to the need to check the trailer and make repairs before the cold storage food is ruined. Even better, by logging this diagnostic data, the compliance with key food transportation safety standards can be shown if needed. Bosona and Gebresenbet [15] demonstrated that technologies such as geographic information systems (GIS) and remote sensing (RS) are used for transportation services and precision analysis, through the collection and integration of data remotely, and for mapping geospatial variability to highlight the movement of goods throughout the entire shipping process. Other real-time tracking technologies such as the IoT, RFID, and blockchain allow easier updates to the shipping process while transporting large-scale food crates from the manufacturing firms to the distributors.

Autonomous vehicles are of great potential in the distribution stage of the food supply chain. This technology is projected to speed up food distribution and reduce the cost of transportation. The prospects for using driverless trucks have been tested rigorously in the recent past. Overall, the adoption of self-driving vehicles in the food sector is anticipated to increase and sustain food transportation through improved access and affordability. According to $\mathrm{Yu}$ and $\mathrm{Yu}$ [29], unmanned or self-driving vehicles with tracking devices can be used in shipping activities if attached to a control system for autonomous driving and a smart system that can be used to detect surrounding objects to prevent collisions. Moreover, delivery service companies can utilize trucks that autonomously drive from one house to another to deliver food packages [63].

There is also a rapidly increasing interest in drones and planes without pilots. Drones have proven their flexibility, efficiency, and effectiveness in adapting to various environments and conditions. Obviously, the wide range and simplicity of applications have led many professionals to focus on developing this technology and utilizing it to its full capacity for different purposes. Leading global retailers, such as Amazon and Walmart, are consistently exploring how best the unmanned aerial vehicles (UAVs) can be adapted to deliver goods to consumers. For consumers in remote areas that are inaccessible by road or rail infrastructure, the use of drones is promising for overcoming these infrastructural challenges [7]. Today, many established, well-known companies such as Amazon, Google, and DHL have become interested in the advanced applications and capabilities of drones and have implemented these technologies in their package deliveries to customers [64]. Small-scale shipping and food deliveries can also be completed using drones with robotic modifications [65]. However, challenges exist for the widespread implementation of these technological innovations in the shipping and delivery components of the food supply chain. These challenges can be attributed primarily to the high costs associated with the upgrading of vehicles or the hiring of affordable UAVs by retailers to deliver food items to customers, which will, in turn, affect the price of the product delivered [66].

\subsubsection{Selling}

Selling is the final point in the process of the food supply chain. Selling is the segment in which retailers ensure that food is available to be purchased by customers, as Figure 1 indicates. The most commonly used technologies in food sales include Point of Sale (POS) technologies, which use an 
electronic registration system to update inventory records. Food retailers also using the IoT to gather and integrate data in real-time to track customer orders and analyze their needs [67].

Smart RFID technology is implemented in the food sector to track the materials produced at any time; to monitor the inventory problems, such as the "Bullwhip Effect," and assist in replenishment and provide the overall performance of the food supply chain [68]. RFID technology also provides real-time location, condition monitoring services, and transaction monitoring services widely used in the selling phase. According to Toyoda et al. [69], RFID technology was very effective for a long time in providing anti-counterfeiting measures in the food supply chain. However, the authenticity of RFID tags cannot be guaranteed anymore because these tags can be easily refabricated in the public space. The authors recommend combining RFID technology with other modern technologies such as the IoT and blockchain to eliminate the effect of counterfeiting and increase efficiency. A blockchain is, in the simplest definition, a time-stamped series of fixed and unalterable data that is recorded and managed by a group of decentralized computers and not owned by any single entity [70]. The blockchain is a highly innovative and revolutionary invention discovered when the first whitepaper called "Bitcoin: A Peer to Peer Electronic Cash System" was released by Satoshi Nakamoto in 2008 to shed light on this technology and to solve a mathematical problem of double-spending [71]. Blockchain technology was most famously used in Bitcoin and electronic transactions until 2014 when professionals started to realize that blockchain technology could be used beyond cryptocurrency. At that point, interested scholars started to search and examine the different areas and applications for blockchain.

Blockchain in the food supply chain can provide innovative resolutions for maintaining the quality of the food being produced. A permanent record of the preserved foods is maintained that cannot be tampered with. Blockchain technology is efficient in sorting out the issues related to agricultural food supply chain traceability by ensuring food safety. This technology has also been found to be efficient in the verification authenticity of the related document in the food supply chain without the requirement of any centralized authority [72]. The application of blockchain technology helps in fulfilling the demand of the government enterprises along with the consumers. It helps bring innovative regulatory ideas to the government and improves the existing flaws of the management. It assures the merchandise quality and gives immediate response to the changing market among the enterprises. Hence, blockchain technology has been efficient in protecting the rights of consumers. Some of the significant features such as immutability and transparency that enables the elimination of fraudulent modifications in the data of the food supply chain have been achieved by blockchain technology. The production system and the consumers can receive real-time delivery concerning the information on the safety status of the food products. Hence, the efficiency, transparency, and low-cost handling of the supply chain is maintained.

The major aim of using blockchain technology in the food supply chain is that it stores the food information in the form of transactions, which are evenly distributed, and seems to be transparent. The transaction in the blockchain network can be validated while all the nodes can trace the food information for achieving transparency and traceability for food safety. Several blocks are used for packaging the transactions in the food supply chain. The data in the blockchain are kept with safety assurance without any sort of manipulation.

\section{Methodology}

This section provides insights into the process used while conducting the present review and describes the methods used to analyze the role of technology in improving the perishable food supply chain in detail.

\subsection{Data Collection}

The research methodology and the data collection method chosen in the present review were mainly based on information collected from secondary sources related to the history of each technology and its implementation in the food supply chain, mainly to improve the efficiency of perishable food. The collected data for analysis based on the papers published are in the English language only, 
with publication dates ranging from 2000 to 2020 to achieve the research objectives. Figure 3 shows a vertical flow chart for the detailed steps of the research methodology:

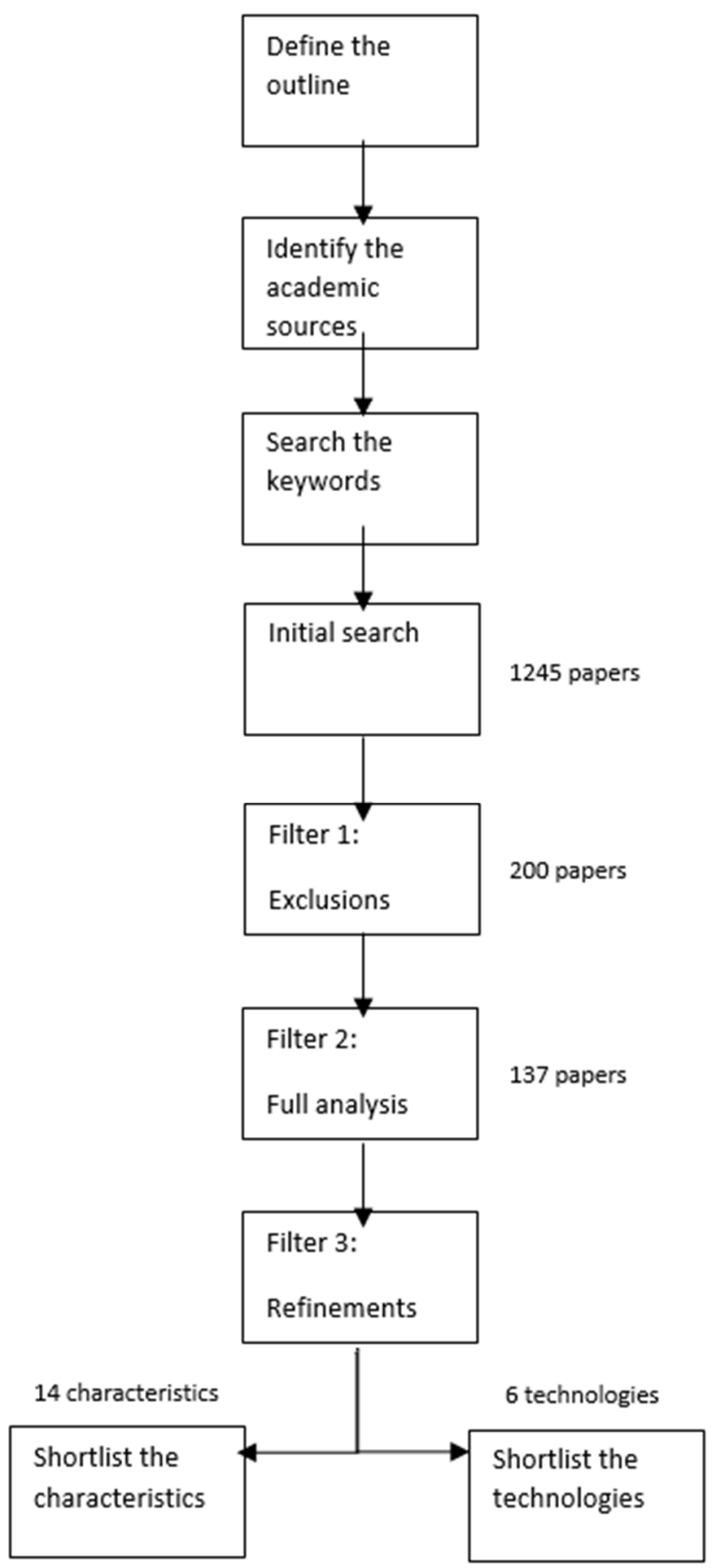

Figure 3. Review methodology. 
Step1: Define the outline.

The outline of the paper was defined by defining the content and selecting the technologies for the review.

Step 2: Identify the academic sources.

The academic sources were identified and used in the data collection stage included and the Qatar National Library (QNL), ProQuest, ScienceDirect, Elsevier, Google Scholar, Wiley, and Institute of Electrical and Electronics Engineers (IEEE). To improve the review's quality, additional sources were considered, including book chapters, conference proceedings, industrial reports, and individual papers such as dissertations.

Step 3: Search the keywords.

The keywords were divided into two sections. The first section was about phases of the food supply chain, and under that specific section, the keywords were "Food supply chain," "Food supply chain management," "Perishable food supply chain," "Food technologies," "Food supply chain sustainability." The second section was to get information specifically for technology selections. The keywords were "Traceability technologies," "Food supply chain technologies," "Supply chain innovation."

Step 4: Initial search.

The initial search generated 1245 papers by skimming through the abstract, introduction, and conclusion.

Step 5: Filter 2-exclusion.

The first filter generated 200 papers by removing duplicate papers. Papers that are not relevant to phases of the food supply chain were also removed.

Step 6: Filter 2-full analysis.

The second filter was applied, and generated 137 papers by thoroughly analyzing the papers and segregating relevant information according to each section, such as history/basic information, phase of the food supply chain, or technology characteristics.

Step 7: Filter 3-refinement.

The third filter was applied to refine the final selection of papers.

Step 8: Shortlist the technologies and characteristics.

The shortlisted of selected technologies from the literature were six, and the shortlisted of the selected characteristics influencing the characteristics of the perishable food supply chain were fourteen out of a total of eighteen.

Figure 4 shows the distribution of research articles per publication in the literature. The graph shows the most cited journals on the topic of this review paper, with the International Journal of Production Economics being the highest with five papers. The next is the Journal of Food Engineering, with four. The Journal of Sensors and Critical Reviews in Food Science and Nutrition are in the third position with three papers. The majority of the journals have a total number of two journals. The "Other journals" bar represents the journals that are cited one time only. There are a total number of 48 such journals available. The book chapters, conference proceedings, industrial reports, and individual papers, such as dissertations were excluded.

\subsection{Data Analysis}

The collected data from the sources were carefully studied to observe and identify similar features or factors among the published studies from different authors to achieve congruence. Table 1 details the methodology used for the literature review framework classification. 


\section{Number of papers}

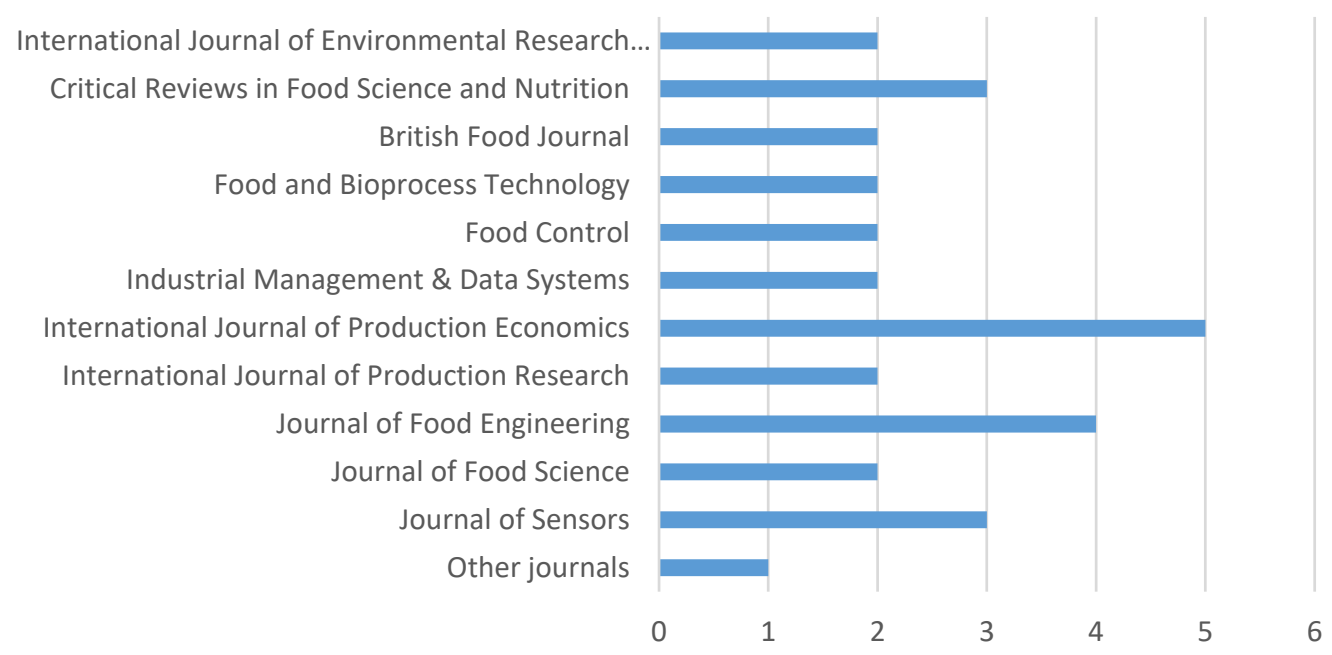

Figure 4. Distribution of research articles in the literature.

Table 1. Literature review classification method.

\begin{tabular}{ccc}
\hline Grouping & Content & Rational \\
\hline $\begin{array}{c}\text { 1. Identification of the factors of } \\
\text { the perishable food supply chain } \\
\text { through literature review }\end{array}$ & $\begin{array}{c}\text { This attempted to identify certain patterns } \\
\text { in the chosen articles in this study. } \\
\text { Both similarities and dissimilarities in } \\
\text { opinions were included in the conceptual } \\
\text { framework of this study. }\end{array}$ & $\begin{array}{c}\text { Such attempts allowed the identification of } \\
\text { the most commonly mentioned features } \\
\text { related to the food to improve the } \\
\text { perishable food supply chain in general. }\end{array}$ \\
$\begin{array}{c}\text { 2. Identification of technologies } \\
\text { used to improve the perishable } \\
\text { food supply chain }\end{array}$ & $\begin{array}{c}\text { Identification of the different technologies } \\
\text { implemented in various stages of the } \\
\text { supply chain to specifically improve } \\
\text { perishable food. }\end{array}$ & $\begin{array}{c}\text { The technological features can be linked to } \\
\text { the general characteristics and factors of a } \\
\text { food supply chain and, therefore, } \\
\text { can explain the implicative opinions of the } \\
\text { authors regarding the connection between } \\
\text { the two and define the requirements and } \\
\text { expectations from such implementations. }\end{array}$ \\
\hline 3. Features of the articles chosen & $\begin{array}{c}\text { The articles chosen in this review cover } \\
\text { topics including the importance of food } \\
\text { supply chains, technological }\end{array}$ & $\begin{array}{c}\text { These articles were chosen to include more } \\
\text { versatility in the literature review. }\end{array}$ \\
& $\begin{array}{c}\text { implementations, different approaches, } \\
\text { and effects of environment controlling } \\
\text { factors on perishable foods. }\end{array}$ & \\
\hline 4. Review and analysis procedure & $\begin{array}{c}\text { This was a structured and textual analysis } \\
\text { comparison among the articles chosen in } \\
\text { the literature review based on keywords. }\end{array}$ & $\begin{array}{c}\text { This was a determination of the different } \\
\text { theories and concepts previously existing } \\
\text { related to the perishable food supply chain. }\end{array}$ \\
\hline
\end{tabular}

\section{Discussion}

The impact of various technologies in different phases of the perishable food supply chain is discussed in the first subsection. The impact of technology integration on various perishable food supply chain characteristics is discussed in the second subsection. Similarly, the impact of technology integration on perishable food supply chain traceability is discussed in the last subsection.

\subsection{Technologies Used in Different Phases of Perishable Food Supply Chain}

The publications selected for this review were based on the technologies that can be used to improve the food supply chain, and they were divided into two main subsections. The first one, technologies widely implemented, such as RFID, IoT, and blockchain. The second section focused on emerging technologies such as three-dimensional printing (3DP), autonomous or self-driving vehicles, and UAVs. Figure 5 below illustrates the overall picture for the technologies discussed in the review for the collected papers that have demonstrated a value addition and improvement to the food supply 
chain. The publications' data were summarized using a basic descriptive statistics tool such as a bar chart to represent the various technologies and their occurrences in Figure 5. As these are basic descriptive statistics, we used MS Excel for these analyses.

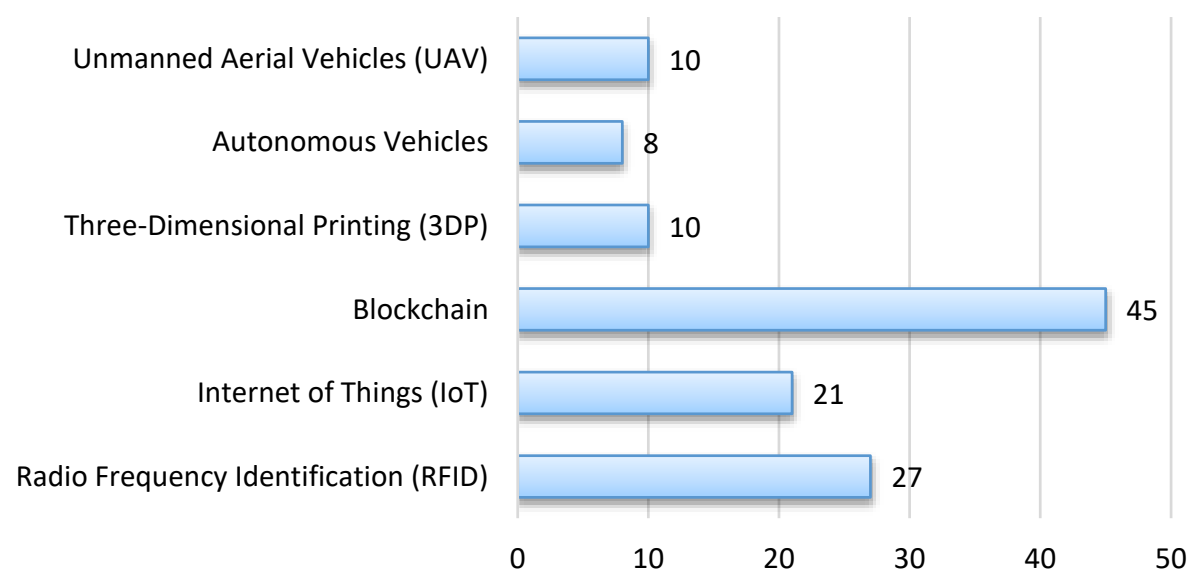

Figure 5. The number of publications related to the technologies used in different phases of the perishable food supply chain.

\subsubsection{Technologies Widely Implemented in the Food Supply Chain}

This section focuses on the technologies that have been widely implemented in the food supply chain sector and positively impacted perishable food. The blockchain has become one of the most trending and disruptive technologies in the supply chain field [73]. According to Mao et al. [74], dealing with the food supply chain is complicated due to its involvement with a multitude of "stakeholders" such as farmers, manufacturers, distributors, retailers, and consumers. For this reason, having a shared and immutable register of foods and transactions would prevent fraud and enable network users to monitor, verify, and accept the transactions. Compared to other types of previously established technologies, blockchain technology has proven advantageous and has demonstrated significant capabilities in improving the food supply chain, such as traceability, transparency, safety, efficiency, and cost-effectiveness [75]. One main characteristic of blockchain technology is the elimination of centralized control in any supply chain, such that no single entity has comprehensive command over the whole process. Another advantage of using blockchain technology is being immutable, and the more parties involved in the transactions of the supply chain, the harder it gets to alter any information [76].

According to Kiviat [77], blockchain resolves issues with untrustworthy transactions in which the presented information is transparent to all network users and requires their approval to move to the next block in the chain. Although some unresolved issues with regards to blockchain technology exist, such as system security and overall privacy [78], scholars and professionals have demonstrated their complete interest in this disruptive technology, which is still in an early phase in its evolution and holds the potential to overcome many potential barriers in the near future [79].

According to Figure 5, the RFID technology is the second most widely used technology in terms of its use in the supply chain to improve efficiency. RFID technology is considered very mature and well established in the field of food supply chains. RFID has been implemented in the food supply chain for use beyond just tracking items or inventories, and RFID tags have been applied to food supply chains to provide full visibility and traceability along the whole chain [80].

Brody et al. [25] proposed RFID technology to trace perishable food packages from their production source to the disposal point. This method for tracking helps monitor food temperatures and ensure food safety and quality. Michael and McCathie [81] studied the different successful applications of RFID technology, such as non-line-of-sight scanning, in which items do not require any specific orientation to be scanned, as well as automatic technology, which can help in labor reduction and 
provide great visibility, traceability, and reliability to the food supply chain. The capacity of this technology has been employed heavily in the agri-food sector, especially in monitoring climates and environments of greenhouses, fire detection, cold chain traceability, farm machinery, precision livestock, and agriculture [19].

Attention should also be drawn to other RFID types that have been used for tracking shipping vehicles to improve their delivery performance and provide better decision-making techniques [67]. Compared to barcodes, RFID technology has proven its ability to transmit information with high speed and accuracy, and in great capacity. However, the main obstacle in this technology, which continually draws criticism from professionals and limits its widespread acceptance, has been its high implementation cost. The cost of the RFID tags ranges anywhere between 25 cents, for short-range tags, and more than $\$ 10$ for specialized long-range tags [82]. Besides, scholars became less interested in talking about RFID technology in their literature from 2016 onwards. Today, RFID technology is integrated with other trendy technologies such as blockchain or the IoT to widen its efficiency and effectiveness and open to frontiers to develop these technologies further. According to Jia et al. [83], RFID is often seen as a prerequisite for the IoT, in which the RFID reader is connected to the Internet to monitor and trace the goods automatically and update the asset system if required.

The Internet of Things is the next technology illustrated in Figure 5 in terms of popularity. It has different applications in food supply chains to improve the efficiency of the perishable food supply. This technology transforms conventional devices into smart and automated networked systems [84]. It has proven its efficiency with the perishable food supply chain while retaining quality, ensuring customers' safety, and facilitating faster responses to changes [85]. Therefore, this technology cannot be employed fully unless it is integrated with other technologies, such as sensors for detection, monitoring, and tracing. They can also be connected to RFID's or blockchain systems to enhance the traceability and reliability of food supply chains [86]. Table 2 summarizes the discussed technologies widely implemented in each phase of the food supply chain.

Table 2. Widely used technologies and their implementation in phases of the food supply chain.

\begin{tabular}{cccc}
\hline Phases & RFID & IoT & Blockchain \\
\hline Agriculture & $\begin{array}{c}\text { Ruiz-Garcia [19]; Costa et al. [37]; } \\
\text { Gautam et al. [80] }\end{array}$ & Ray [22] & Kamilaris et al. [34] \\
\hline $\begin{array}{c}\text { Transformation and } \\
\text { Processing }\end{array}$ & $\begin{array}{c}\text { Gaukler and Seifert [82]; Brody et al. [25]; } \\
\text { Costa et al. [37] }\end{array}$ & Li et al. [28] & \\
\hline Packaging & Gaukler and Seifert [82]; Brody et al. [25] & Li et al. [28] & \\
\hline Shipping & Angeles [31]; Gaukler \& Seifert [82]; & & $\begin{array}{c}\text { Jeppsson \& Olsson [30]; } \\
\text { Petersen et al. [50] }\end{array}$ \\
\hline Selling & $\begin{array}{c}\text { Angeles [37]; Gaukler \& Seifert [81]; } \\
\text { Sarac et al. [68]; Toyoda et al. [69] }\end{array}$ & Toyoda et al. [69] \\
\hline
\end{tabular}

\subsubsection{Emerging Technologies and Their Implementation in Phases of the Food Supply Chain}

This subsection explains the emerging technologies and their great potentials although, these technologies are less developed in the food supply chain, and their implementations are still limited due to high cost and other reasons tied to ethics. For instance, 3D printing, also known as additive manufacturing, has recently received increased public attention, and is considered a game-changer. Moreover, 3D printing has been implemented in different phases of the food supply chain, such as production, in which 3DP has enabled food customization based on specific requirements. Food products were made based on received orders and whenever they were required, thus helping to reduce the inventory and minimize the instability in the product's demand and supply in the supply chain known as the "Bullwhip Effect" [24]. 
According to $\mathrm{Hu}$ et al. [87], 3DP is an intelligent and flexible technology that is suitable for producing complex products in small batches with lower costs and reduced waste in time and material. However, 3DP has not been integrated well in the food supply chain and has not delivered on its maximum potential due to some ethical issues, which are yet to be resolved with this technology, such as theft of intellectual property and counterfeit products [43]. The most debatable issue is 3D printing meat, which aims to provide consumers with higher quality proteins compared to vegetables and to reduce the pressure on the agriculture sector. Recently, Australia has sponsored an ethical research program for uncovering and highlighting community concerns related to this emerging technology [24].

Autonomous or self-driving vehicles and unmanned aerial vehicles are considered the last two technologies illustrated in Figure 5. These technologies can improve the supply chain, and, hence, food security, by promoting faster and convenient access to affordable foods by consumers. Autonomous vehicles have proven their ability in a wide range of applications in the food supply chain. Self-driving vehicles have demonstrated great agriculture achievements, such as smart farming, mechanical weeding, fertilizer application, and harvesting of fruits and vegetables [23]. They have also been utilized for the delivery and distribution stages of the food supply chain. This technology has increased the speed of food distribution, which reduces labor and transportation costs. They have proved their reliability over humans, especially in dealing with road systems, thus improving safety and reducing potential accidents [88]. According to Bagloee et al. [89], the emerging technology of autonomous vehicles has applications beyond what people can expect and has contributed to reducing transportation costs, thus resolving mobility issues for low-income households.

UAVs can be considered intelligent technologies with various successful use cases. The main advantage of this technology is its ability to operate at high altitudes, giving the vehicles the capabilities for overall control in three dimensions. The food supply chain has experienced a considerable increase in its efficiency after using this emerging technology in its applications. According to Carrio et al.'s [90] review, UAVs are currently applied in diverse civilian and military applications, including search and rescue, monitoring harvests, security, warehouse organization, and goods deliveries. The simple benefits of UAVs can be extended to more complex applications by attaching cameras to drones for multiple purposes, adding GPS for location finding and deliveries, or connecting sensors for farm monitoring and wildlife tracking [20]. Table 3 detail a summary of the discussed emergent technologies and their implementation in each phase of the food supply chain.

Table 3. Emerging technologies and their implementation in phases of the food supply chain.

\begin{tabular}{cccc}
\hline Phases & 3DP & AV & UAV \\
Agriculture & & Walter et al. [23] & $\begin{array}{c}\text { Zhang and Kovacs [20]; } \\
\text { Beloev [65]; Walter et al. [23]; } \\
\text { Carrio et al. [90] }\end{array}$ \\
\hline $\begin{array}{c}\text { Transformation and } \\
\text { Processing }\end{array}$ & $\begin{array}{c}\text { Sun et al. [24]; Hu et al. [87]; } \\
\text { Godoi et al. [46]; Li et al. [28]; } \\
\text { Chan et al. [91] }\end{array}$ & & \\
\hline Packaging & Lu and Wang [62] & Forrest and Konca [63]; & Beloev [65]; Carrio et al. [90]; \\
Shipping & Chan et al. [91] & $\begin{array}{c}\text { Davidson and Spinoulas [88]; } \\
\text { Yu and Yu [29]; Bagloee et al. [89] }\end{array}$ & $\begin{array}{c}\text { Hassanalian and Abdelkefi [64] } \\
\text { Selling }\end{array}$ \\
\hline
\end{tabular}

\subsection{Technology Integration to Improve Perishable Food Supply Chains}

The review of published studies has confirmed that technologies have been applied to all the stages in the food supply chain from farm to fork, all of which directly impact the efficiency of the perishable food provided. Most of the technologies used for the perishable food supply chain and referred to by authors in the literature have considered modifications to adapt to the surrounding 
environment, especially in the case of the food supply chain, since it is one of the most complex supply chains. Figure 6 provides a summary of several publications covered with characteristics discussed in the reviewed literature. Some of these characteristics were explicitly mentioned in the authors' study, whereas other studies only referred to these factors. The publications' data were summarized using a basic descriptive statistics tool such as a bar chart to represent the various characteristics and their occurrences in Figure 6. As these are basic descriptive statistics, we used MS Excel for these analyses.

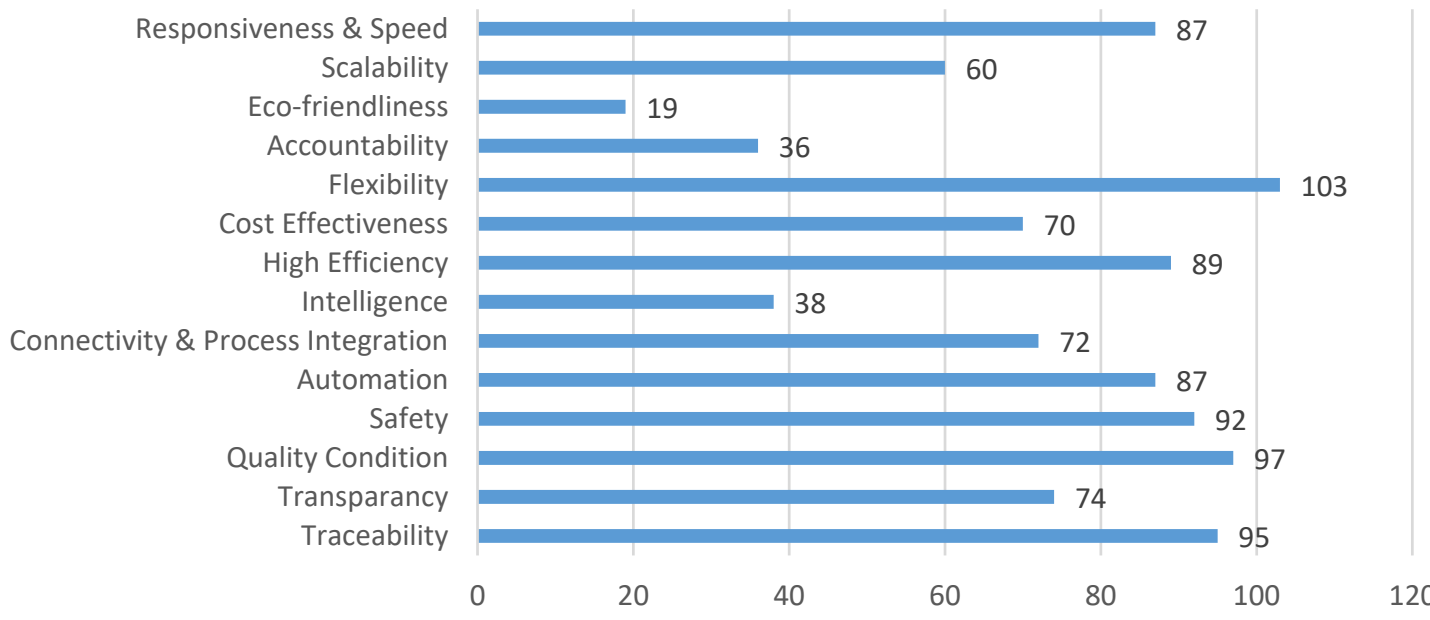

Figure 6. Characteristics of integrating technologies to improve the perishable food supply chain.

\subsubsection{Impact of Integrating Technologies on the Characteristics of the Perishable Food Supply Chain}

Implementing technologies has many advantages, the most important of which is providing some levels of flexibility to cope with any changing circumstances and deal with them effectively and efficiently [17]. The flexibility factor has the highest rate of perceived importance compared to other factors, as it is critical to the deployment of new technology. An examination of the different studies in the review indicates that the traceability, transparency, quality, and safety characters are the most frequently mentioned features for perishable foods. Most of the studies also identified other features, such as high efficiency for the provided food and low costs for all the systems' activities. However, most of the focus of the scholars was on the traceability character, as it indicates transparency and ensures the safety and quality of perishable foods. These characters were considered the most crucial for the proper functioning of the whole perishable food supply chain. Technologies, such as RFID, the IoT, and blockchain are good examples of technologies used for traceability and transparency to improve the safety and quality of perishable foods. These technologies can provide perishable foods with higher efficiency and lower costs. According to Kshetri [61], a blockchain can be deployed easily in any organization free of attachment to supporting expensive devices food products compared to RFID.

In this era, the food industry is more critical, and customer needs mainly drive it. Fulfilling these needs requires the dependency on partial or full automation to speed up the response time and gain customer satisfaction and loyalty [11]. As such, factors, such as automation and speedy responsiveness, have been the focus and frequently mentioned in many papers for their importance when handling perishable foods. Other studies have pointed to other essential features, such as connectivity and process integration. This can be achieved by integrating more than one type of technology to align the interests and gain a unified view of the food supply chain [17]. Scalability was extremely obvious using 3D printing, which can customize according to the required customer order size or seasonality [17]. According to the review, this has effectively contributed to the reduction of suppliers, laborers, and inventories, as well as the Bullwhip Effect. Instead, the same technology has been promoted for made-to-order products, even in one single customized unit, if needed [91]. 
Through the review of literature from 2000 to 2020, related to technology implementation in improving the perishable food supply chain, it can be deduced that the majority of studies did not directly consider how these technologies can be utilized to support environmental sustainability and an eco-friendly food industry. Some authors have considered the impact of these technologies on the environmental sustainability of the perishable food supply chain. For instance, Mao et al. [74] have designed in their research paper a novel Food Trading System with Consortium blockchain (FTSCON) to eliminate information asymmetry in the food trade to establish a sustainable and credible trading environment. They have selected the blockchain technology with its huge capabilities to deal with the challenges of the complex food supply chain and allow the collaboration between their different actors. Pohlmann et al. [92] discussed the different roles of the focal company and their importance in achieving sustainable development goals (SDGs). However, the eco-friendliness factor was either mentioned or indirectly referred to quite often by some authors, who understood the importance of reusing more than $95 \%$ of the waste materials for recycling and reuse to ensure sustainability, similar to the closed-loop of the meat supply chain highlighted by the study conducted by Khan et al. [93]

\subsubsection{Impact of Integrating Technologies on the Traceability of the Perishable Food Supply Chain}

The RFID tracking chips have demonstrated their effectiveness in enhancing traceability in the movement of food products within the supply chain [31]. RFID technology can minimize manual work errors in the supply chain, thus improving quality, including the freshness and safety of foods. RFID technology can facilitate efficient and effective observation of items within the food supply chain at a reduced labor cost. RFID technology can be implemented in a wide range of situations for almost all products in the food supply chain, such as fruits, vegetables, meat, dairy products, bakery products, seafood, amongst others [37].

According to Kim et al. [94], RFID is used to identify vehicle locations during shipping to optimize vehicle operations for maximum cost-effectiveness. In addition, RFID tags are applied in the food supply chain to automate warehouse and distribution centers to eliminate errors by ensuring that the correct product and quantities are located at the right point for the collection. Kelepouris et al. [67] clearly demonstrated the significance of the RFID technology in optimizing various supply chain processes, thereby promoting consumer access to the food items.

Within traceability objectives, cloud and internet technologies are used to identify, locate, and track the status of assets in real-time. Technologies that advance IoT systems facilitate data retrieval, storage, analytics, and connectivity across the supply chain [2]. This is essential in the traceability of perishable foods to achieve the required quality and safety standards. The IoT and cloud technologies can be used at any stage of the food value chain to gather better data and deliver faster and more precise decisions [95]. Moreover, blockchain technology can be applied in the food supply chain to provide precise information about the required food product [96]. Widespread agreement exists that this technology holds promise in supporting traceability in the perishable food supply chain, which the factors classification illustrated in Figure 3 illustrate. The figure indicates the key factors of using technologies to improve the perishable food supply chain, and the number of studies related to blockchain indicates the importance of blockchains.

Blockchain technologies are highly useful in creating a transparent traceability service throughout the food supply chain [97]. Furthermore, by creating a smooth and complete flow of information in the food supply chain, blockchain promotes transparency among producers, distributors, suppliers, and other players within the food system. Therefore, enabling the provision of a clear path depicting the product movement process from raw material acquisition to the financial consumption stage [98].

\section{Review Findings}

Figure 7 is a block diagram showing interrelations between the technologies and the characteristics of the perishable food supply chain. The technologies were divided into two major categories. The first section shows those widely implemented, and the second section shows the emerging 
technologies. The blockchain, RFID, and IoT are technologies that have been implemented widely, and have hugely influenced the characteristics of the perishable food supply chain. Moreover, 3DP, $\mathrm{UAV}$, and autonomous vehicles are also technologies found in the food supply chain; however, they are still new, and their applications are not widely spread worldwide. Certain technologies may have more impact on some characteristics that influence the perishable food than others.

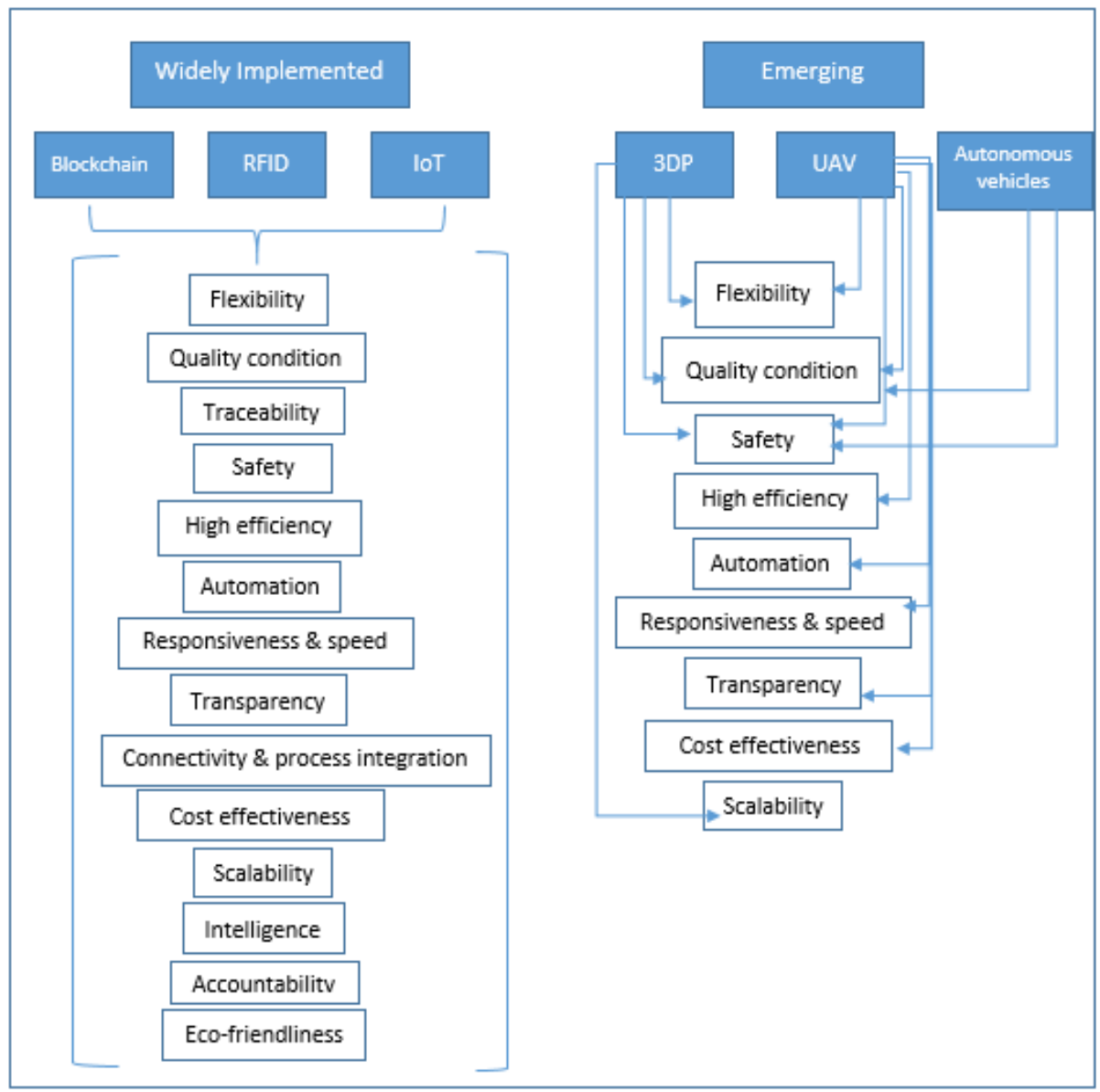

Figure 7. Interrelations between technologies and characteristics of perishable food supply chain.

The findings of this review are provided as follows:

Blockchain: most exchanges and transactions in any supply chain or a food supply chain specifically involve different parties who do not know or trust each other, and in most cases, they do not work for the same organization. Although the blockchain has been found to influence all characteristics of perishable food, the main impact is the high level of safety it can provide compared to other types of technologies. For blockchain, only authorized individuals are provided with access to food transactions.

Any modification or update to a transaction requires the concurrence of all entities of the food supply chain. The entered information is immutable; once entered, the information has to be validated by more than one entity, which eliminates control being centralized. The more entities involved in the food supply chain, the harder it will be to modify or change a transaction. This technology is also an excellent choice for traceability and can provide visibility of perishable food in real-time to ensure the consumer's food quality. Implementing blockchain technology in the food supply chain is inexpensive compared to the returns, which requires an upfront investment only to set up a dedicated IT infrastructure as a transaction base.

RFID: RFID technology is well established in the food supply chain, and its applications are well implemented in many phases of the food supply. RFID technology has influenced all characteristics of perishable food. However, the major implications of RFID are seen in characteristics like traceability, 
speed, and automation. RFID technology can easily track, trace, and reveal the history of any perishable product to ensure the product's safety and quality. RFID technology can facilitate efficient and effective observation of items within the food supply chain, reduce human interactions, and minimize manual work errors in the food supply chain.

RFID technology influences the speed characteristics and the responsiveness of the perishable food supply chain. It can be used to detect and identify food product information for efficient operation automatically. This encourages more output from this technology in a shorter period. This technology is not as safe as the blockchain, as counterfeiters can easily duplicate the tracking chips.

IoT: the smart devices that are remotely connected to each other and with the digital networks are gaining great popularity in the technology's world due to their massive capabilities. This technique has proven its ability to reduce costs because the implementation required only the cost of connecting to a digital platform. The IoT technologies are mainly influencing perishable food traceability if implemented in the food supply chain. Therefore, these technologies are used to identify, locate, and track the status of perishable food in real-time.

IoT technology has greatly influenced the flexibility and scalability characteristics of the perishable food supply chain. The IoT influenced the flexibility characteristics in how IoT provides convenience to people where smart devices can be reached, managed easily by individuals. IoT technology has also influenced scalability in which more people and devices can easily be connected to each other.

3DP: 3DP technology is an emerging but promising technology in the food supply chain. Moreover, 3DP offers the possibility of enhancing and customizing food per a customer's individual requirements. This technology will impact flexibility, assisting in reducing the number of suppliers and workers, and eliminating production facilities. Production can take place anywhere, and a dedicated facility is not required. Furthermore, 3DP can influence scalability characteristics where production can be scaled up or down based on different seasonality or customer's demand.

UAV: the UAV is another emerging but promising technology in the food supply chain. There are various applications for UAV technology mainly implemented in the food supply chain for deliveries. The UAV has influenced flexibility characteristics due to its ability to carry packages of various shapes and sizes and serve different purposes.

UAVs are more flexible in reaching areas that are difficult to reach and deliver fresh food during harsh weather conditions or service seniors. The UAV also impacts speed and responsiveness because deliveries can reach their final destinations very fast. UAVs have been used recently to monitor agricultural fields and examine fresh crops closely to guarantee successful harvesting.

Autonomous Vehicles: autonomous vehicles offer great promise in the distribution stage of the food supply chain. This technology greatly influences speed and responsiveness characteristics to meet customers' demands in a short period. Autonomous vehicle technology will decrease the cost of transportation. Autonomous vehicle technology is also influencing safety characteristics because fewer people will need to drive, which, in turn, will reduce the number of accidents.

\section{Conclusions}

The review involved the analysis of the ideas presented in various studies related to the implementation of technology, and to identify technologies used in different phases of the food supply chain, such as agriculture, processing, packaging, shipping, and selling, and to evaluate their effectiveness in improving the characteristics of perishable foods. The primary outcomes of the review indicated that most of the studies agree on the significant benefits gained through implementing and integrating technologies into the food supply chain systems. The array of different technologies available for integration in the different phases of a food supply chain. The first section includes the widely implemented technologies such as blockchain, RFID, and IoT while the second section includes 3DP, UAV, and autonomous vehicles. These technologies were found in different phases of the food supply chain and improved the efficiency of supplying perishable foods. 
Different characteristics of perishable food supply chains and a block diagram showing Interrelations between the technologies and the characteristics of the perishable food supply chain are identified in this review, as a major typology gained through reviewing the technological implementation for improving perishable food features. Evidently, the use of technologies in the food supply chain can contribute to the improvement of perishable food in the predefined conditions by customers. Technologies are mainly applied to improve perishable food traceability and procedural transparency and ensure food quality and safety. The use of technology will also reduce the full dependency on labor, which will assist in reducing human error and costs, as well as ensuring the cost-effective delivery of food to most people, especially those with limited incomes. This, in turn, leads, to increases in a firm's efficiency and competitiveness in the food supply chain sector, particularly with perishable foods.

Author Contributions: Conceptualization, M.H. and T.A.-A.; methodology, M.H., L.K., M.M., and T.A.-A.; software, M.H.; formal analysis, M.H.; data curation, M.H.; writing-original draft preparation, M.H.; writing-review and editing, L.K., M.M., and T.A.-A.; visualization, L.K.; supervision, T.A.-A.; project administration, T.A.-A. All authors have read and agreed to the published version of the manuscript.

Funding: This research received no external funding.

Acknowledgments: This publication was made possible by the GSRA grant, ID\# (GSRA5-1-0602-18119), from the Qatar National Research Fund (a member of Qatar Foundation). The contents herein are solely the responsibility of the authors.

Conflicts of Interest: The authors declare no conflict of interest.

\section{References}

1. Ashley, J.M. Food Security in the Developing World; Senior International Consultant, Geopolicity Inc.: Dubai, UAE, 2016.

2. Tian, F. An Information System for Food Safety Monitoring in Supply Chains Based on HACCP, Blockchain and INTERNET of Things. Doctoral Dissertation, Wirtschafts Wien University of Economics and Business, Wien, Austria, 2018. Available online: https://epub.wu.ac.at/6090/1/Dissertation_of_Feng_Tian.pdf (accessed on 11 November 2020).

3. Hammoudi, A.; Grazia, C.; Surry, Y.; Traversac, J.B. (Eds.) Food Safety, Market Organization, Trade and Development; Springer: Berlin/Heidelberg, Germany, 2015.

4. Jaynes, R.S.; Darlington, S. The Federal Food Safety Working Group Working Groups Process and Assessments; Nova Science Publisher, Inc.: New York, NY, USA, 2013.

5. Paam, P.; Berretta, R.; Heydar, M.; Middleton, R.H.; García-Flores, R.; Juliano, P. Planning models to optimize the agri-fresh food supply chain for loss minimization: A review. In Reference Module in Food Science; Elsevier: Amsterdam, The Netherlands, 2016; pp. 19-54. [CrossRef]

6. Pang, Z.; Chen, Q.; Han, W.; Zheng, L. Value-centric design of the internet-of-things solution for food supply chain: Value creation, sensor portfolio and information fusion. Inf. Syst. Front. 2015, 17, 289-319. [CrossRef]

7. Marsden, T.; Banks, J.; Bristow, G. Food supply chain approaches: Exploring their role in rural development. Sociol. Rural. 2000, 40, 424-438. [CrossRef]

8. Khan, Z.H.; Khalid, A.; Iqbal, J. Towards realizing robotic potential in future intelligent food manufacturing systems. Innov. Food Sci. Emerg. Technol. 2018, 48, 11-24. [CrossRef]

9. Farahani, P.; Grunow, M.; Günther, H.O. Integrated production and distribution planning for perishable food products. Flex. Serv. Manuf. J. 2012, 24, 28-51. [CrossRef]

10. Lemma, Y.; Kitlaw, D.K.; Gatew, G. Loss in perishable food supply chain: An optimization approach literature review. Int. J. Sci. Eng. Res. 2014, 5, 302-311.

11. Aung, M.M.; Chang, Y.S. Temperature management for the quality assurance of a perishable food supply chain. Food Control 2014, 40, 198-207. [CrossRef]

12. Markina, I.; Safonov, Y.; Zhylinska, O.; Diachkov, D.; Varaksina, E. Defining the dimensions of national security, financial security and food supply chain in Ukraine. Int. J. Supply Chain Manag. 2018, 7, 608-620.

13. Smith, D.; Sparks, L. Temperature controlled supply chains. In Food Supply Chain Management; Bourlakis, M.A., Weightman, P.W.H., Eds.; Blackwell Publishing: Oxford, UK, 2004; pp. 179-198. 
14. Balaji, M.; Arshinder, K. Modeling the causes of food wastage in Indian perishable food supply chain. Resour. Conserv. Recycl. 2016, 114, 153-167. [CrossRef]

15. Bosona, T.; Gebresenbet, G. Food traceability as an integral part of logistics management in food and agricultural supply chain. Food Control 2013, 33, 32-48. [CrossRef]

16. Squire, B.; Burgess, K.; Singh, P.J.; Koroglu, R. Supply chain management: A structured literature review and implications for future research. Int. J. Oper. Prod. Manag. 2006, 26, 703-729. [CrossRef]

17. Büyüközkan, G.; Göçer, F. Digital supply chain: Literature review and a proposed framework for future research. Comput. Ind. 2018, 97, 157-177. [CrossRef]

18. Opara, L.U. Traceability in agriculture and food supply chain: A review of basic concepts, technological implications, and future prospects. J. Food Agric. Environ. 2003, 1, 101-106.

19. Ruiz-Garcia, L.; Lunadei, L.; Barreiro, P.; Robla, I. A review of wireless sensor technologies and applications in agriculture and food industry: State of the art and current trends. Sensors 2009, 9, 4728-4750. [CrossRef] [PubMed]

20. Zhang, C.; Kovacs, J.M. The application of small unmanned aerial systems for precision agriculture: A review. Precis. Agric. 2012, 13, 693-712. [CrossRef]

21. Dasgupta, N.; Ranjan, S.; Mundekkad, D.; Ramalingam, C.; Shanker, R.; Kumar, A. Nanotechnology in agro-food: From field to plate. Food Res. Int. 2015, 69, 381-400. [CrossRef]

22. Ray, P.P. Internet of Things for smart agriculture: Technologies, practices and future direction. J. Ambient Intell. Smart Environ. 2017, 9, 395-420. [CrossRef]

23. Walter, A.; Finger, R.; Huber, R.; Buchmann, N. Opinion: Smart farming is key to developing sustainable agriculture. Proc. Natl. Acad. Sci. USA 2017, 114, 6148-6150. [CrossRef] [PubMed]

24. Sun, J.; Zhou, W.; Huang, D.; Fuh, J.Y.; Hong, G.S. An overview of 3D printing technologies for food fabrication. Food Bioprocess Technol. 2015, 8, 1605-1615. [CrossRef]

25. Brody, A.L.; Bugusu, B.; Han, J.H.; Sand, C.K.; Mchugh, T.H. Innovative food packaging solutions. J. Food Sci. 2008, 73, 107-116. [CrossRef]

26. Duncan, T.V. Applications of nanotechnology in food packaging and food safety: Barrier materials, antimicrobials and sensors. J. Colloid Interface Sci. 2011, 363, 1-24. [CrossRef]

27. Ghaani, M.; Cozzolino, C.A.; Castelli, G.; Farris, S. An overview of the intelligent packaging technologies in the food sector. Trends Food Sci. Technol. 2016, 51, 1-11. [CrossRef]

28. Li, Z.; Liu, G.; Liu, L.; Lai, X.; Xu, G. IoT-based tracking and tracing platform for prepackaged food supply chain. Ind. Manag. Data Syst. 2017, 117, 1906-1916. [CrossRef]

29. Yu, S.S.; Yu, S. U.S. Patent Application No. 15/648,532. 2017. Available online: https://patentimages.storage. googleapis.com/1e/1b/f9/0f5fad7ed629a8/US20170308098A1.pdf (accessed on 11 November 2020).

30. Jeppsson, A.; Olsson, O. Blockchains as a Solution for Traceability and Transparency. Master's Thesis, Lund University, Lund, Sweden, 2017. Available online: https:/lup.lub.lu.se/student-papers/search/ publication/8919957 (accessed on 11 November 2020).

31. Angeles, R. RFID technologies: Supply-chain applications and implementation issues. Inf. Syst. Manag. 2005, 22, 51-65. [CrossRef]

32. Pfaltzgraff, L.A.; Clark, J.H. Green chemistry, biorefineries and second generation strategies for re-use of waste: An overview. In Advances in Biorefineries; Waldron, K., Ed.; Woodhead Publishing: Cambridge, UK, 2014; pp. 3-33. [CrossRef]

33. Taticchi, P.; Garengo, P.; Nudurupati, S.S.; Tonelli, F.; Pasqualino, R. A review of decision-support tools and performance measurement and sustainable supply chain management. Int. J. Prod. Res. 2015, 53, 6473-6494. [CrossRef]

34. Kamilaris, A.; Fonts, A.; Prenafeta-Bold v́, F. The rise of the blockchain technology in agriculture and food supply chain. Inst. Agric. Food Res. Technol. 2018, 91, 1-15. [CrossRef]

35. Sufiyan, M.; Haleem, A.; Khan, S.; Khan, M.I. Analyzing attributes of food supply chain management: A comparative study. In Advances in Industrial and Production Engineering; Shanker, K., Shankar, R., Sindhwani, R., Eds.; Lecture Notes in Mechanical Engineering; Springer: Singapore, 2019. [CrossRef]

36. Pagnon, W. Overview of techniques and applications for autonomous vehicles. Lovotics 2014, 1, $106-107$. [CrossRef]

37. Costa, C.; Antonucci, F.; Pallottino, F.; Aguzzi, J.; Sarriá, D.; Menesatti, P. A review on agri-food supply chain traceability by means of RFID technology. Food Bioprocess Technol. 2013, 6, 353-366. [CrossRef] 
38. Kros, J.F.; Liao, Y.; Kirchoff, J.F.; Zemanek, J.E., Jr. Traceability in the supply chain. Int. J. Appl. Logist. (IJAL) 2019, 9, 1-22. [CrossRef]

39. Prakash, G. Review of the food processing supply chain literature: A UK, India bilateral context. J. Adv. Manag. Res. 2018, 15, 457-479. [CrossRef]

40. Rong, A.; Akkerman, R.; Grunow, M. An optimization approach for managing fresh food quality throughout the supply chain. Int. J. Prod. Econ. 2011, 131, 421-429. [CrossRef]

41. Arunachalam, D.; Kumar, N.; Kawalek, J.P. Understanding Big Data Analytics capabilities in supply chain management: Unravelling the issues, challenges and implications for practice. Transp. Res. Part E Logist. Transp. Rev. 2018, 114, 416-436. [CrossRef]

42. Dubey, R.; Gunasekaran, A.; Childe, S.J.; Papadopoulos, T.; Fosso Wamba, S. World class sustainable supply chain management: Critical review and further research directions. Int. J. Logist. Manag. 2017, 28, 332-362. [CrossRef]

43. Dick, A.; Bhandari, B.; Prakash, S. 3D printing of meat. Meat Sci. 2019, 153, 35-44. [CrossRef]

44. Ricci, I.; Derossi, A.; Severini, C. 3D printed food from fruits and vegetables. In Fundamentals of 3D Food Printing and Applications; Godi, F.C., Bhandari, B.R., Prakash, S., Zhang, M., Eds.; Elsevier: Amsterdam, The Netherlands, 2019; pp. 117-149. [CrossRef]

45. Kumar, R.; Kumar, R. 3D printing of food materials: A state of art review and future applications. Mater. Today Proc. 2020. [CrossRef]

46. Godoi, F.C.; Prakash, S.; Bhandari, B.R. 3D printing technologies applied for food design: Status and prospects. J. Food Eng. 2016, 179, 44-54. [CrossRef]

47. Singh, A.; Mishra, N.; Ali, S.I.; Shukla, N.; Shankar, R. Cloud computing technology: Reducing carbon footprint in beef supply chain. Int. J. Prod. Econ. 2015, 164, 462-471. [CrossRef]

48. Manning, L.; Soon, J.M. Building strategic resilience in the food supply chain. Br. Food J. 2016, 118, 1477-1493. [CrossRef]

49. Mogale, D.G.; Kumar, M.; Kumar, S.K.; Tiwari, M.K. Grain silo location-allocation problem with dwell time for optimization of food grain supply chain network. Transp. Res. Part E Logist. Transp. Rev. 2018, 111, 40-69. [CrossRef]

50. Petersen, M.; Hackius, N.; von See, B. Mapping the sea of opportunities: Blockchain in supply chain and logistics. It-Inf. Technol. 2018, 60, 263-271. [CrossRef]

51. Óskarsdóttir, K.; Oddsson, G.V. Towards a decision support framework for technologies used in cold supply chain traceability. J. Food Eng. 2019, 240, 153-159. [CrossRef]

52. Verghese, K.; Lewis, H.; Lockrey, S.; Williams, H. Packaging's role in minimizing food loss and waste across the supply chain. Packag. Technol. Sci. 2015, 28, 603-620. [CrossRef]

53. Pal, M. Nanotechnology: A new approach in food packaging. J. Food Microbiol. Saf. Hyg. 2017, 2, 1000121. [CrossRef]

54. Almasi, H.; Jahanbakhsh Oskouie, M.; Saleh, A. A review on techniques utilized for design of controlled release food active packaging. Crit. Rev. Food Sci. Nutr. 2020. [CrossRef] [PubMed]

55. Chen, S.; Brahma, S.; Mackay, J.; Cao, C.; Aliakbarian, B. The role of smart packaging system in food supply chain. J. Food Sci. 2020, 85, 517-525. [CrossRef]

56. Tianfei, D. Automatic control of food packaging machinery. In IOP Conference Series: Earth and Environmental Science; IOP Publishing: Bristol, UK, July 2020; Volume 546, p. 052067.

57. Tripathi, S.; Shukla, S.; Attrey, S.; Agrawal, A.; Bhadoria, V.S. Smart industrial packaging and sorting system. In Strategic System Assurance and Business Analytics; Springer: Singapore, 2020; pp. 245-254.

58. Wu, D.; Zhang, M.; Chen, H.; Bhandari, B. Freshness monitoring technology of fish products in intelligent packaging. Crit. Rev. Food Sci. Nutr. 2020, 1-14. [CrossRef]

59. Urbano, O.; Perles, A.; Pedraza, C.; Rubio-Arraez, S.; Castelló, M.L.; Ortola, M.D.; Mercado, R. Cost-effective implementation of a temperature traceability system based on Smart RFID Tags and IoT Services. Sensors 2020, 20, 1163. [CrossRef]

60. Liegeard, J.; Manning, L. Use of intelligent applications to reduce household food waste. Crit. Rev. Food Sci. Nutr. 2020, 60, 1048-1061. [CrossRef] [PubMed]

61. Kshetri, N. Blockchain's roles in meeting key supply chain management objectives. Int. J. Inf. Manag. 2018, 39, 80-89. [CrossRef] 
62. Lu, S.; Wang, X. Toward an intelligent solution for perishable food cold chain management. In 2016 7th IEEE International Conference on Software Engineering and Service Science (ICSESS); IEEE: Piscataway, NJ, USA, August 2016; pp. 852-856.

63. Forrest, A.D.; Konca, M. Autonomous Cars \& Society. Digital WPI. 2007. Available online: https://digitalcommons. wpi.edu/cgi/viewcontent.cgi? article=3253\&context=iqp-all (accessed on 11 November 2020).

64. Hassanalian, M.; Abdelkefi, A. Classifications, applications, and design challenges of drones: A review. Prog. Aerosp. Sci. 2017, 91, 99-131. [CrossRef]

65. Beloev, I.H. A review on current and emerging application possibilities for unmanned aerial vehicles. Acta Technol. Agric. 2016, 19, 70-76. [CrossRef]

66. Xiang, H.; Tian, L. Development of a low-cost agricultural remote sensing system based on an autonomous unmanned aerial vehicle (UAV). Biosyst. Eng. 2011, 108, 174-190. [CrossRef]

67. Kelepouris, T.; Pramatari, K.; Doukidis, G. RFID-enabled traceability in the food supply chain. Ind. Manag. Data Syst. 2007, 107, 183-200. [CrossRef]

68. Sarac, A.; Absi, N.; Dauzère-Pérès, S. A literature review on the impact of RFID technologies on supply chain management. Int. J. Prod. Econ. 2010, 128, 77-95. [CrossRef]

69. Toyoda, K.; Mathiopoulos, P.T.; Sasase, I.; Ohtsuki, T. A novel blockchain-based product ownership management system (POMS) for anti-counterfeits in the post supply chain. IEEE Access 2017, 5, 17465-17477. [CrossRef]

70. Prajapati, S.; Dwivedi, P.; Dubey, A.D.; Singh, M.; Chaturvedi, S. Introduction to Blockchain. Int. J. Sci. Res. Rev. 2019, 7, 1800-1805.

71. Nakamoto, S. Bitcoin: A Peer-to-Peer Electronic Cash System. Bitcoin. Org. 2008. Available online: https://bitcoin.org/bitcoin.pdf (accessed on 4 November 2020).

72. Duan, J.; Zhang, C.; Gong, Y.; Brown, S.; Li, Z. A content-analysis based literature review in blockchain adoption within food supply chain. Int. J. Environ. Res. Public Health 2020, 17, 1784. [CrossRef] [PubMed]

73. Salah, K.; Rehman, M.H.U.; Nizamuddin, N.; Al-Fuqaha, A. Blockchain for AI: Review and open research challenges. IEEE Access 2019, 7, 10127-10149. [CrossRef]

74. Mao, D.; Wang, F.; Hao, Z.; Li, H. Credit evaluation system based on blockchain for multiple stakeholders in the food supply chain. Int. J. Environ. Res. Public Health 2018, 15, 1627. [CrossRef]

75. Galvez, J.F.; Mejuto, J.C.; Simal-Gandara, J. Future challenges on the use of blockchain for food traceability analysis. Trac Trends Anal. Chem. 2018, 107, 222-232. [CrossRef]

76. Treiblmaier, $\mathrm{H}$. The impact of the blockchain on the supply chain: A theory-based research framework and a call for action. Supply Chain Manag. Int. J. 2018, 23, 545-559. [CrossRef]

77. Kiviat, T.I. Beyond bitcoin: Issues in regulating blockchain transactions. Duke Law J. 2015, 65, 569-608.

78. Saadé, R.G.; Jaoude, J.N.A.; Sharma, M.C. Review of blockchain Literature-Its application and acceptance. In Proceedings of the Informing Science and Information Technology Education Conference, Jerusalem, Israel, 30 June-4 July 2019; pp. 297-306. [CrossRef]

79. Saberi, S.; Kouhizadeh, M.; Sarkis, J.; Shen, L. Blockchain technology and its relationships to sustainable supply chain management. Int. J. Prod. Res. 2019, 57, 2117-2135. [CrossRef]

80. Gautam, R.; Singh, A.; Karthik, K.; Pandey, S.; Scrimgeour, F.; Tiwari, M.K. Traceability using RFID and its formulation for a kiwifruit supply chain. Comput. Ind. Eng. 2017, 103, 46-58. [CrossRef]

81. Michael, K.; McCathie, L. The pros and cons of RFID in supply chain management. In Proceedings of the International Conference on Mobile Business (ICMB'05), Sydney, New South Wales, Australia, 11-13 July 2005; pp. 623-629. [CrossRef]

82. Gaukler, G.M.; Seifert, R.W. Applications of RFID in supply chains. In Trends in Supply Chain Design and Management; Jung, H., Jeong, B., Chen, F.F., Eds.; Springer Series in Advanced Manufacturing; Springer: London, UK, 2007; pp. 29-48. [CrossRef]

83. Jia, X.; Feng, Q.; Fan, T.; Lei, Q. RFID technology and its applications in Internet of Things (IoT). In Proceedings of the 2nd International Conference on Consumer Electronics, Communications and Networks, Yichang, China, 21-23 April 2012; IEEE: Piscataway, NJ, USA, 2012; pp. 1282-1285. [CrossRef]

84. Reyna, A.; Martín, C.; Chen, J.; Soler, E.; Díaz, M. On blockchain and its integration with IoT. Challenges and opportunities. Future Gener. Comput. Syst. 2018, 88, 173-190. [CrossRef] 
85. Bhayani, M.; Patel, M.; Bhatt, C. Internet of Things (IoT): In a way of smart world. In Proceedings of the International Congress on Information and Communication Technology; Bhatt, S.S.Y., Joshi, A., Mishra, D., Eds.; Advances in Intelligent Systems and Computing; Springer: Singapore, 2016; Volume 438, pp. 343-350. [CrossRef]

86. Tian, F. A supply chain traceability system for food safety based on HACCP, blockchain \& Internet of things. In Proceedings of the 2017 International Conference on Service Systems and Service Management, Dalian, China, 16-18 June 2017; IEEE: Piscataway, NJ, USA, 2017; pp. 1-6.

87. Hu, F.; Li, L.I.; Liu, Y.; Yan, D. Enhancement of agility in small-lot production environment using 3D printer, industrial robot and machine vision. Int. J. Simul. Syst. Sci. Technol. 2016, 17, 32-37. [CrossRef]

88. Davidson, P.; Spinoulas, A. Autonomous vehicles: What could this mean for the future of transport? In Proceedings of the Australian Institute of Traffic Planning and Management (AITPM) National Conference, Brisbane, QLD, Canada, 28-31 July 2015; Available online: http://transposition.com.au/papers/ AutonomousVehicles.pdf (accessed on 11 November 2020).

89. Bagloee, S.A.; Tavana, M.; Asadi, M.; Oliver, T. Autonomous vehicles: Challenges, opportunities, and future implications for transportation policies. J. Mod. Transp. 2016, 24, 284-303. [CrossRef]

90. Carrio, A.; Sampedro, C.; Rodriguez-Ramos, A.; Campoy, P. A review of deep learning methods and applications for unmanned aerial vehicles. J. Sens. 2017, 3296874. [CrossRef]

91. Chan, H.K.; Griffin, J.; Lim, J.J.; Zeng, F.; Chiu, A.S. The impact of 3D Printing Technology on the supply chain: Manufacturing and legal perspectives. Int. J. Prod. Econ. 2018, 205, 156-162. [CrossRef]

92. Pohlmann, C.R.; Scavarda, A.J.; Alves, M.B.; Korzenowski, A.L. The role of the focal company in sustainable development goals: A Brazilian food poultry supply chain case study. J. Clean. Prod. 2020, 245, 118798. [CrossRef]

93. Khan, M.J.; Kumari, S.; Selamat, J.; Shameli, K.; Sazili, A.Q. Reducing meat perishability through pullulan active packaging. J. Food Qual. 2020. [CrossRef]

94. Kim, J.; Tang, K.; Kumara, S.; Yee, S.T.; Tew, J. Value analysis of location-enabled radio-frequency identification information on delivery chain performance. Int. J. Prod. Econ. 2008, 112, 403-415. [CrossRef]

95. Verdouw, C.N.; Wolfert, J.; Beulens, A.J.M.; Rialland, A. Virtualization of food supply chains with the Internet of things. J. Food Eng. 2016, 176, 128-136. [CrossRef]

96. Tse, D.; Zhang, B.; Yang, Y.; Cheng, C.; Mu, H. Blockchain application in food supply information security. In Proceedings of the 2017 IEEE International Conference on Industrial Engineering and Engineering Management (IEEM), Singapore, 10-13 December 2017; pp. 1357-1361. [CrossRef]

97. Sander, F.; Semeijn, J.; Mahr, D. The acceptance of blockchain technology in meat traceability and transparency. Br. Food J. 2018, 120, 2066-2079. [CrossRef]

98. Thakur, M.; Hurburgh, C.R. Framework for implementing traceability system in the bulk grain supply chain. J. Food Eng. 2009, 95, 617-626. [CrossRef]

Publisher's Note: MDPI stays neutral with regard to jurisdictional claims in published maps and institutional affiliations.

(C) 2020 by the authors. Licensee MDPI, Basel, Switzerland. This article is an open access article distributed under the terms and conditions of the Creative Commons Attribution (CC BY) license (http://creativecommons.org/licenses/by/4.0/). 